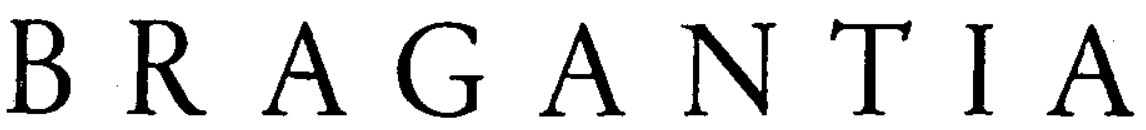

Boletim Técnico do Instituto Agronômico do Estado de Sáo Paulo

Vol. 21

Campinas, janeiro de 1962

N.0 3

\title{
DESENVOLVIMENTO DO SISTEMA RADICULAR DO ALGODOEIRO NA CAMADA ARÁVEL DO SOLO $^{1}$
}

A. C. Magalhães, engenheiro-agrônomo, Seção de Fisiologia, M. G. Fuzatto, I. L. Gridi-PAPP e W. Schmidt, engenheiros-agrônomos, Seção de Algodão, Instituto Agronômico

\section{RESUMO}

Sabe-se que o sistema rọdicular do algodoeiro se situo predominantemente na regiăo compreendida pelos primeiros $20 \mathrm{~cm}$ de profundidade do solo. Como a cultura exige intensas práticas culturais, torna-se útil conhecer a distribuição progressiva do sistema radicular naquela região, sobretudo nos primeiros meses do ciclo vegetativo. éfoca em que a cultura exige o intensificação das capinos. Estudos sôbre a questão foram efetuados em um ensaio de campo com a variedade IAC 12-57/566, em solo tipo terra-roxa-misturado, fazendo-se observações aos 42, 61 e 81 dias após a germinação das sementes.

Os dados mostraram maior concentração de raizes na camada de 3 a $15 \mathrm{~cm}$ de profundidade do solo e cté a umo distância aproximada de $25 \mathrm{~cm}$ lateralmente ̀̀s plantas. O ritmo de crescimento do sistemo radicular do algodoeiro foi mais intenso do $42 .^{\circ}$ oo $61 .^{\circ}$ dia opós a germinação.

A má utilização dos implementos agrícolas nesse período mais critico, podfrá pois, provacar grandes danos à cultura, principalmente se forem empregados cultivos p-ofundos.

\section{1 - INTRODUÇÃO}

Sendo o algodoeiro muito sensível à concorrência das ervas más, necessárias se tornam práticas agrícolas intensas, a fim de conservar o terreno limpo na maior parte do ciclo vegetativo.

Cavaleri e Inforzato (1) constataram que, independentemente da variedade e do tipo de solo, cêrca de $80 \%$ do pêso total das raízes do algodoeiro estão localizadas nos primeiros $20 \mathrm{~cm}$ de solo. Hall e outros (3), em estudos com fósforo radiativo, verificaram que a parte

1 Recebido para publicação em 16 de dezembro de 1961. 
mais ativa do sistema radicular dessa planta, constituída pelas radicelas, situa-se nos primeiros $30 \mathrm{~cm}$ de solo.

Devido à grande concentração de raízes finas na camada superior do solo, é óbvio que o algodoeiro poderá ser grandemente prejudicado pelo uso de implementos impróprios, pelos cultivos profundos. Aliás, observa-se, na prótica, certa relação entre o "shedding" acentuado e o uso do "bico de pato", implemento de cultivo relativamente profundo, de uso muito comum no Estado de São Paulo. Leonard (6) mostrou que a pressão radicular do algodoeiro é sensivelmente reduzida quando as raízes são cortadas a cêrca de $10 \mathrm{~cm}$ de profundidade do solo e $15 \mathrm{~cm}$ ao redor da planta. Com o aumento da profundidade, e até certo limite, maior número de raízes serão atingidas, provocando um decréscimo no poder de absorção da planta, com relação aos elementos minerais do solo.

Eaton e Joham (2), citando outros autores, concluem que a absorção dos nutrientes do solo pelo algodoeiro aumento desde o início do crescimento vegetativo até o florescimento, sofrendo uma diminuição quando entra no período de maturação.

Mendes (5), estudando a nutrição de algodoeiros em solução nutritiva, mostrou que a absorção dos elementos $\mathrm{N}, \mathrm{P}, \mathrm{K}$ e Ca foi máxima no período compreendido entre 30 e 60 dias do ciclo vegetativo. Verificou ainda que, ao se abrirem os primeiros capulhos (120 dias), o algodoeiro pràticamente já havia absorvido $90 \%$ do total dos elementos $\mathrm{N}, \mathrm{P}, \mathrm{K}, \mathrm{Ca}, \mathrm{Mg}, \mathrm{S}$ e Fe.

Considerando todos êsses fatos, projetou-se o estudo relatado neste trabalho, e no qual se procurou conhecer a distribuição progressiva do sistema radicular da planta nos primeiros $20 \mathrm{~cm}$ de solo e na primeira metade do ciclo vegetativo, periodo em que as raízes estão mais sujeitas aos danos acarretados pelos trabalhos de cultivo.

\section{2 - MATERIAL E MÉTODO}

O estudo foi conduzido num campo de algodão (Gossypium hrrsutum L.) do variedade IAC 12-57/566, plantado com o espaçamento de $0,80 \times 0,15 \mathrm{~m}$, em solo tipo terra-roxa-misturada, na Estação Experimental "Theodureto de Camargo", em Campinas. Fêz-se a semeadura em linha contínua, por meio de semeadeira, em 28 de outubro de 
1960. As plantas emergiram em 4 de novembro de 1960 e o desbaste foi feito 25 dias após a germinação, deixando-se cinco a sete plantas por metro linear.

O terreno, que já havia sido cultivado anteriormente com algodão, recebeu adubação de sulfato de amônio, superfosfato e cloreto de potássio, na proporção de 30,60 e $60 \mathrm{~kg}$ por ha de $\mathrm{N}, \mathrm{P}_{2} \mathrm{O}_{5}$ e $\mathrm{K}_{2} \mathrm{O}$, respectivamente.

Além das capinas manuais, como trato cultural obrigatório, obedeceu-se a um esquema de combate preventivo às pragas da cultura, iniciado 10 dias após a germinação, sendo levadas a efeito, aproximadamente sete pulverizações.

No campo foram selecionados três lotes, nos quais as plantas se apresentavam bem homogêneas quanto ao desenvolvimento. Em cada lote foi aberta uma valeta para o estudo do sistema radicular, quando as plantas contavam 42, 61 e 81 dias de idade após a germinação, isto é, em 16 de dezembro de 1960, 4 e 24 de janeiro de 1961, respectivamente.

O método empregado foi semelhante ao utilizado por Cavaleri e Inforzato (1). Todavia, êstes autores estudaram o sistema radicular da planta adulta, com 4-5 meses de idade. No presente trabalho o interêsse foi conhecer o desenvolvimento progressivo das raizes, isto é, aos 40,60 e 80 dias após a germinação das plantas, cingindo-se as observações à camada constituída pelos primeiros $20 \mathrm{~cm}$ do solo, uma vez que nela se concentram $80 \%$ do pêso total do sistemo radicular do algodoeiro (1).

Cavaleri e Inforzato (1), estudaram a distribuição do sistema radicular retirando blocos de solo ao longo das linhas de plantas. Neste trabalho as valetas foram abertas no sentido transversal ao das linhas, abrangendo a parede que foi desmanchada em blocos, quatro linhas com três plantas cada. Esta parede foi subdividida em cinco camadas, mantendo-se as sinuosidades da superfície do terreno, a fim de que mesmo as radicelas mais superficiais fôssem levadas em consideração, pois estas, apesar de acusarem pêso quase insignificante, desempenham papel de considerável importância na absorção da água $\mathrm{e}$ nutrientes do solo.

No sentido do seu maior comprimento, a parede foi dividida em 20-21 blocos, e os cinco níveis de profundidade, estudados a partir da 
superfície do terreno, formaram as seguintes camadas: $1 .^{a}$, de 0 a $3 \mathrm{~cm}$ de profundidade; $2^{a}, 3-6 \mathrm{~cm} ; 3 .{ }^{a}, 6-10 \mathrm{~cm} ; 4^{a}, 10-15 \mathrm{~cm}$ e $5{ }^{a}$, $15-20 \mathrm{~cm}$.

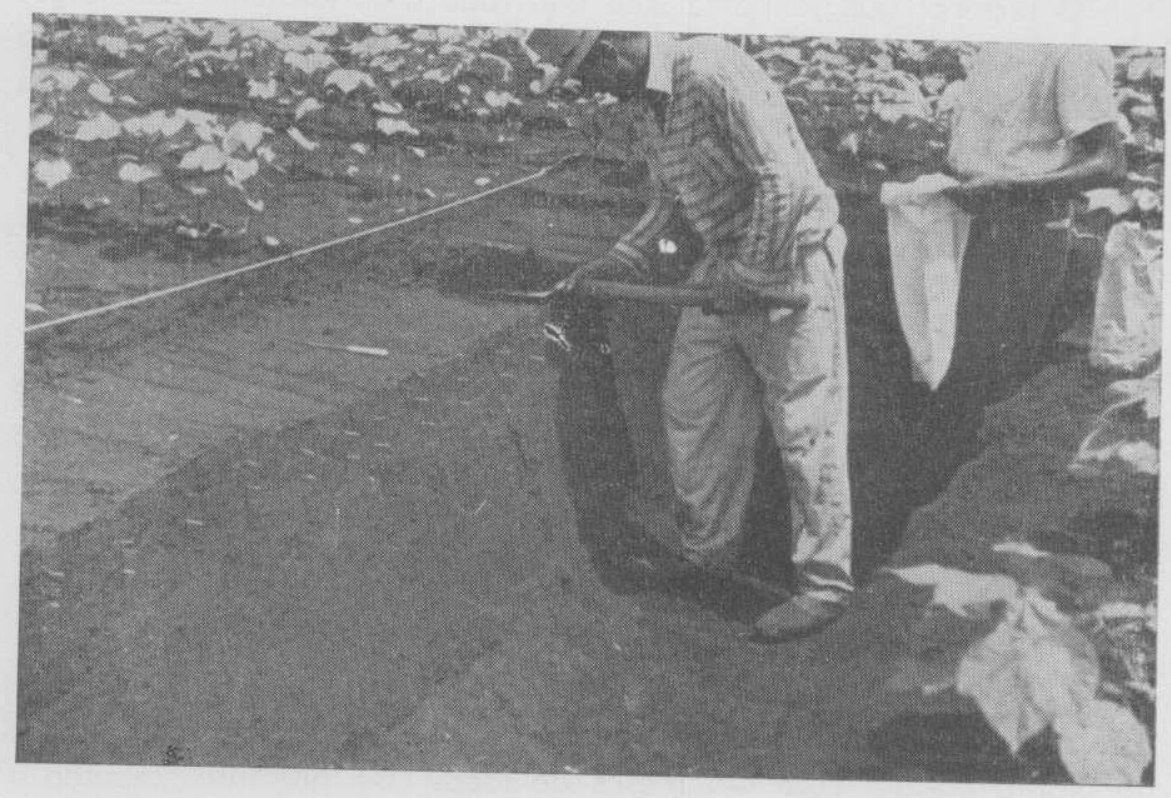

Figura 1. - Valeta aberta para o estudo do sistema radicular do algodoeiro.

A largura média dos blocos foi de $16 \mathrm{~cm}$, havendo uma variação nesta dimensão, provocada pela necessidade de perfeito enquadramento das plantas dentro dos blocos. O comprimento dêstes foi sempre de $50 \mathrm{~cm}$. Por ocasião da retirada dos blocos, mediram-se as alturas das plantas.

A terra correspondente a cada bloco foi sêca ao ar e em seguida peneirada, a fim de se separar as raízes. Estas, após lavagem e secagem ao ar, foram cuidadosamente pesadas, com aproximação de um miligrama.

Em prancha apropriada foram desenhados os perfis de todos os blocos de terra retirados em cada época de estudo, e as raízes correspondentes a cada bloco, depois de sêcas, foram distribuídas no respectivo retângulo e ai fotografadas em conjunto. 


\section{3 - RESUltAdOS E DISCUSSÃO}

As alturas médias das plantas em cada época considerada foram as seguintes: $1 .^{a}-25 \mathrm{~cm} ; 2 .^{a}-59 \mathrm{~cm} ; 3 .^{a}-95,5 \mathrm{~cm}$.

Do quadro 1 constam os dados relativos aos pesos das raízes nas diferentes idades estudadas, e na figura 2 reproduziu-se, fotogràfi-camente, a sua distribuição pelas diferentes camadas consideradas.

QUADRo 1. - Dados relativos à distribuiçāo progressiva do sistema radicular do algodoeiro no solo tipo terra-roxa-misturada, quando foram considerados três estágios do desenvolvimento da plonta e os primeiros $20 \mathrm{~cm}$ de solo.

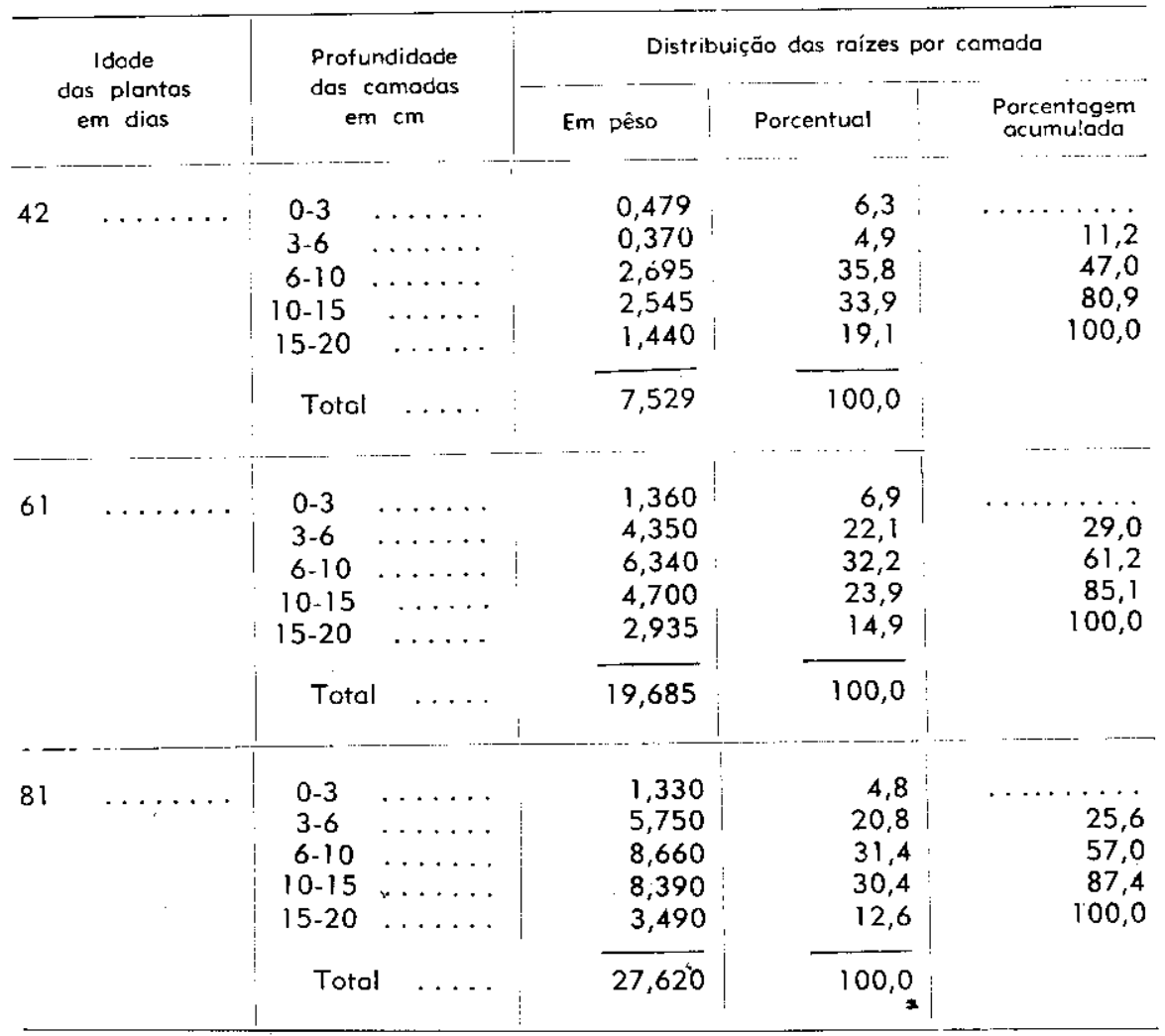




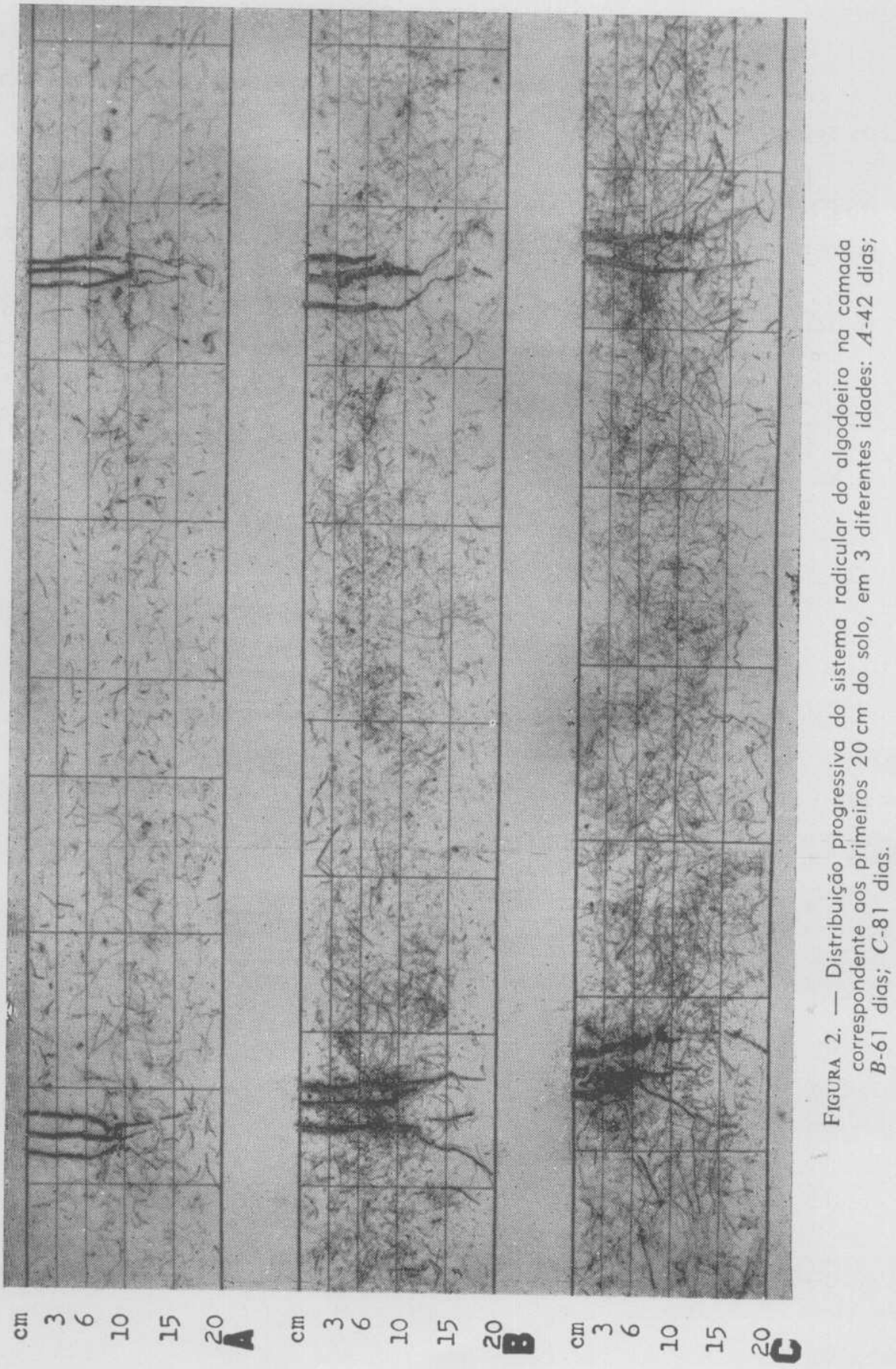


Analisando os dados do quadro 1, verifica-se que a distribuição porcentual das raízes do algodoeiro se concentrou nas camadas do solo que vão dos 6 aos $15 \mathrm{~cm}$ e $3-15 \mathrm{~cm}$ de profundidade, nas idades de 42 dias, 61-81 dias, respectivamente. Estas faixas encerram de 70 a $82 \%$ do total das raizes contidas nos primeiros $20 \mathrm{~cm}$ do solo.

Com a idade de 42 dias, o pêso total das raízes foi relativamente pequeno, com predominância de raízes finas.

Aos 61 dias, o sistema radicular do algodoeiro assumiu uma distribuição mais homogênea, abrangendo principalmente a faixa compreendida entre as profundidades de 3 até $15 \mathrm{~cm}$. Esta camada apresentou, aproximadamente, $80 \%$ do total das raizes encontradas no perfil estudado. Nessa época, a penetração lateral das raizes foi considerável e sua distribuição, no sentido transversal às linhas de plantio, tornou-se mais uniforme. O maior adensomento das raizes deu-se até mais ou menos $25 \mathrm{~cm}$ lateralmente às plantas. Houve grande concentração de raízes na camada de $3 \circ 6 \mathrm{~cm}$ de profundidade (figura 2), que não pode ser atribuída ao efeito do cultivo, pois no ensaio só foram feitos tratos superficiais com enxada.

A terceira e última observação, contando as plantas com 81 dias de idade, mostrou uma acumulação de raízes (mais de $82 \%$ ) localizadas na camada de 3 a $15 \mathrm{~cm}$ de profundidade, e distribuídas de maneira mais ou menos uniforme. Nessa ocasião o sistema radicular

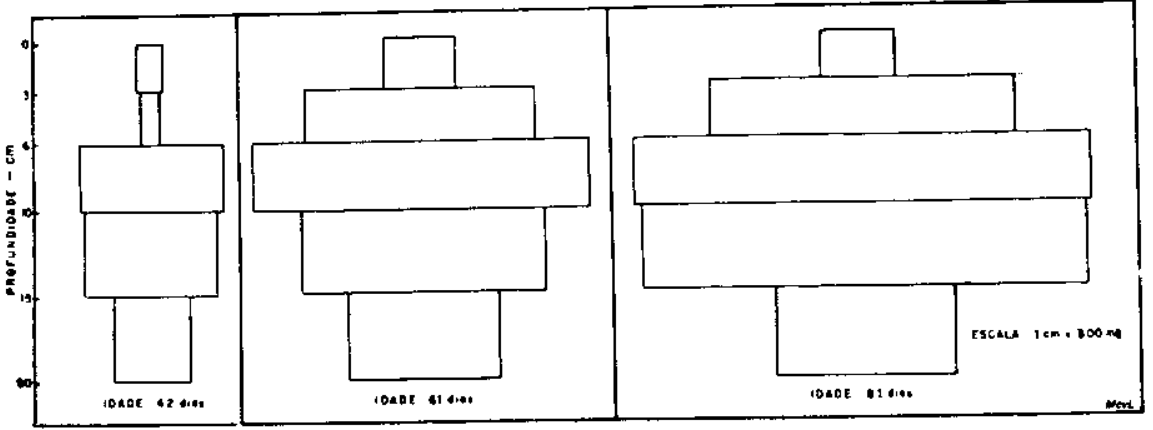

Figura 3. - Representoçāo da distribuição do sistemo radicular do algodoeiro na camada correspondente aos primeiros $20 \mathrm{~cm}$ do solo, em diferentes idades.

do algodoeiro apresentava-se muito subdividido, mostrando uma grande quantidade de radicelas. Lateralmente às plantas, a localização das raízes obedecia a uma distribuição homogênea dentro das profundidades já mencionadas, havendo um entrelaçamento das raizes das plantas das diversas linhas. 
Uma comparaçāo entre o pêso total das raízes do algodoeiro nas três diferentes idades, mostra grande aumento no crescimento do sistema radicular a partir do $42 .^{\circ}$ até o $61 .^{\circ}$ dia, épocas em que foram feitas as duas primeiras determinações. Daí até o $811^{\circ}$ dia, o sistema radicular do algodoeiro continuou num ritmo de crescimento menos intenso. Conforme se disse anteriormente, os tratos culturais se restringiram a capinas superficiais a enxada, evitando-se a meconização, a fim de permitir o livre desenvolvimento dos raízes nas primeiras comadas aqui estudadas.

Essa distribuição, com grande concentração de raízes finas na camada mais superficial do solo, pode ser explicada através das propriedades físicas e químicas do terra-roxa-misturada, na qual as plantas estavam vegetando. Pelas boas condiçōes de aeração e drenagem e pela apreciável fertilidade, fornece a terra-roxa-misturada condições muito favoráveis para o desenvolvimento do sistema radicular do algodoeiro, que aí chega a atingir profundidades de até $2,50 \mathrm{~m}(1)$.

Um solo com umidade a aeração favoráveis, proporciona às raizes um meio ótimo para o seu crescimento e subdivisão, resultando daí uma superfície de absorção considerável. Assim, cuidados especiais devem ser dispensados quando do emprêgo de implementos agrícolas que possam provocar danos à cultura. O "bico de pato", por exemplo, que atinge, freqüentemente, uma profundidade de $10 \mathrm{~cm}$, iria ocasionar a perda de mais de $50 \%$ do total das raízes localizadas nos primeiros $20 \mathrm{~cm}$ do solo, quando empregado entre 40 e 80 dias após a germinaçāo.

\section{4 - CONCLUSÕES}

Pela análise dos resultados obtidos podem-se tirar as seguintes conclusões:

1 - No perfil de solo estudado, de $20 \mathrm{~cm}$ de profundidade, as raízes do algodoeiro se concentraram principalmente nas camadas de 6 a $15 \mathrm{~cm}$ e de 3 a $15 \mathrm{~cm}$, respectivamente aos 42 e $61-81$ dias de idade. Nessas camadas foram sempre encontradas mais de $70 \%$ das rázes existentes no mencionado perfil. Êstes dados mostram a importância da limpeza sistemática das fileiras, sobretudo no início do desenvolvimento do algodoeiro, para eliminar a concorrência das ervas más. 
2 - Nas idades consideradas, o algodoeiro apresentou maior adensamento de raízes até uma distância de aproximadamente $25 \mathrm{~cm}$ lateralmente às plantos.

3 - O crescimento do sistema radicular processou-se em ritmo muito intenso a partir do $42 .^{\circ}$ até o $61 .^{\circ}$ dia, quando apresentou uma quantidade de raízes 3,5 vêzes superior à inicial; daí até o $811^{\circ}$ dia, as raizes atingiram o dôbro da quantidade observada quando da segunda determinação.

4 - A partir do $61 .^{\circ}$ dia, as raízes do algodoeiro já se mostravam bem entrelaçadas nas entrelinhas.

5 - Houve considerável aumento no porcentagem de raízes compreendidas na camada de 3 a $6 \mathrm{~cm}$ de profundidade, entre as idades de 42 e 61 dias. É nessa época que o algodoeiro requer cultivos mais frequientes. Consequientemente, os danos cousados por cultivos profundos seriam maiores nessa época; daí a necessidade de fazê-los tão rasos quanto possível.

\section{DISTRIBUTION OF COTTON ROOTS IN THE UPPER SOIL LAYERS AT THREE DIFFERENT TIME INTERVALS}

\section{SUMMARY}

The distribution of the cotton plant root system in the upper $20 \mathrm{~cm}$ layer of soil was studied at three different times $(42,61$ and 81 -day old plants). These studies were carried out in a cotton field of the variety IAC 12-57/566 planted on a "terra-roxa-misturado" type of soil. The spacing was $80 \mathrm{~cm}$ between rows and $15 \mathrm{~cm}$ between plonts in tive row.

The method employed consisted in excavating a ditch of a right angle to the plant rows, including four plants, and then removing the soil as blocks. Five layers of soil blocks were taken: the first and second were $3 \mathrm{~cm}$ thick; the third, $4 \mathrm{~cm}$ thick; and the fourth and fifth, $5 \mathrm{~cm}$ thick. After washing off the soil of each block, the roots in it were air dried and weighed.

A representation of the root distribution as encountered is given in figure 2 . For the cotton field studied, most of the roots were found between 3 and $15 \mathrm{~cm}$ of depth up to a distance of $25 \mathrm{~cm}$ from the plant stem. Between 42 and 61 day; of oge, the cotton plants developed an appreciable amount of roots in the soil layer lying between the depths of 3 and $6 \mathrm{~cm}$.

It is recommended that much care must be taken in regard to cultivating cotton fields since a large amount of roots is found in upper $6 \mathrm{~cm}$ layer of soil which is frequently reached by the cultivator. 


\section{LITERATURA CITADA}

1. CAVALERI, P. A. \& INFORZATO, R. Estudo do sistema radicular do algodreirn nos três principais tipos de solo do Estado de São Paulo. Brogantia 15:[337]-346. 1956.

2. EATON, F. M. \& JOHAM, H. E. Sugar movement to roots, mineral uptake and the growth of the cotton plant. Plant Physiol. 19:507-518. 1944.

3. HALL, N. S., CHANDLER, W. F., BAVEL, C. H. M. van [e outros]. A tracer technique to measure growth and activity of plant root systems. Raleigh, North Caroline agric. Exp. Sta., 1953. 40 p. (Tech. Bull. N. 101)

4. LEONARD, $O$. A. Use of root pressures in determining injury to roots by cultivotion. Plant Physiol. 19:157-163. 1944.

5. MENDES, H. C. Nutrição do algodoeiro. II. Absorção mineral por plantas vegetondo em soluções nutritivas. Bragantia 19:[435]-458. 1960. 